\title{
Inter-Edge and Cloud conversion accelerated user-generated content for virtual brand community
}

\author{
Mengmeng Song, Yucong Duan *iD, Tianyi Huang and Lougao Zhan
}

\begin{abstract}
Web-based enterprises have increasingly begun to build their own virtual brand community on the Cloud. How to encourage Web users to generate Web content in the Web community continuously and permanently has become the focal point. However, few studies have explored that how to drive the motivation of user-generated content (UGC) named self-enhancement (SE) internalized from the perspective of user's personal characteristics and then enhance the intention of UGC. Even fewer studies have been devoted to drive the motivation of UGC from the perspective of information technology. Based on self-construal (SC) theory, self-determination (SD) theory, and current immersive applications of Edge computing, we proposed to a solution of user-generated content motivation internalized in the virtual brand community implemented through the manipulation of the tradeoff of inter-Edge and Cloud processing. Our survey shows that different types of self-construal (SC) users have different levels of internal motivation for self-enhancement (SE) accomplished through the organization of user characteristics. We build a detailed simulation of the change of time delay, availability, and cost of inter-Edge and Cloud conversion to demonstrate the feasibility of our proposed mechanism of UGC motivation internalized in the virtual brand community in guiding enhancing the intention of UGC in the community in practice.
\end{abstract}

Keywords: Edge computing, Inter-Edge and Cloud conversion, Self-construal, Self-determination theory, Selfenhancement, User-generated content

\section{Introduction}

With the rapid development of various network technology especially Cloud computing $[1,2]$ and Edge computing $[3,4]$, traditional marketing methods are undergoing great changes, and various forms of virtual brand communities in social networks [5] take advantage of the trend. Starbucks, Xiaomi, Huawei, Samsung, and other enterprises have successively established their virtual brand communities. The platform mechanism of twoway interaction enables enterprises not only pays attention to their published content, but also more eager to hear more users' voices in the community $[6,7]$. Meanwhile, the social function of the networked community and even mobile network [8] also provides great convenience for the communication between users and narrowing the psychological distance between them [9]. Therefore, compared with existing market-generated

\footnotetext{
* Correspondence: duanyucong@hotmail.com
}

Hainan University, Haikou, China content (MGC) in the networked community, more and more users choose to trust user-generated content (UGC) in the community [10-13]. Relative to the late specializing in the professionally generated content (PGC), although its content quality is more assured, because its cost is higher, UGC still has a certain advantage with its cheap, wide, and fast update features, welcomed by the enterprise. In a word, with the accumulated support of the virtual brand community accelerated through Cloud and Edge applications, UGC has not only emerged in large numbers, but also become an extremely valuable strategic marketing resource [18], take Xiaomi community as an example. As of March 2019, there were 37 million posts in the community, and the huge amount of UGC has become an important source of product innovation of Xiaomi. However, compared with active users, there are still a considerable number of lurking users in the community. Many virtual brand 
communities are faced with problems such as low user stickiness and insufficient generated content $[15,16]$.

As the release subject of UGC, it is easier to grasp the changes in users' psychology and motivation from the perspective of their own characteristics [17]. It is not hard to find that, however, the existing studies mostly still stay at the level of motivation itself, lacking discussion on the fundamental factors affecting the internalization of motivation, especially the characteristics of community users. Although to some extent it can explain how to promote UGC intention, the problem is how to effectively promote the internalization of motivations which affect the UGC intention. This is because the internally motivated group believes that activities are pleasant and satisfying and will identify with the social rules and integrate them into itself, so as to persist for a long time and produce positive behavioral results [18-20]. In fact, China has the traditional culture of attaching importance to social relations. Similarly, virtual brand communities connect consumers with common brand preferences and needs. Community values are also created based on establishing or maintaining good relationships between users and brands and promoting UGC [21]. Then, it is still a problem whether there is a close relationship between the internal motivation of UGC and the social and relatedness needs (RNs) generated by the users in the community. More importantly, as the main body of the community, users define SC types through how to deal with their relations with others and then display corresponding needs, motivations, and behavioral tendencies [22, 23]. Therefore, if we cannot deeply understand the formation mechanism of the internalization of UGC motivation from the perspective of users, it is difficult for enterprises [24] to carry out socialized marketing according to different types of users. For this purpose, this study introduces the theories of self-construal (SC) and self-determination (SD) to explore the differences in the needs of different types of SC users in the community and the further impact on the motivation and intention of UGC triggered by this.

Towards converting the lurking users to active UGC contributors, many studies have focused on the impact of external motivations represented by platform incentive mechanism on UGC intention [15, 23]. Some scholars start from internal motivation to explore how to motivate users to generate more content. Research conducted by Kamboj et al. shows that internal motivations, including entertainment and brand preference, can significantly stimulate value-creating behaviors such as UGC in the community [25]. Yang believes that with the popularity of independent media, satisfaction and altruism become important drivers for users to generate content [26]. Toubia and Stephen summarized two motivations for users to initiate and forward UGC, including intrinsic utility and image-related utility [27].
This paper is a further study of this part with a combination of the implementation strategy of inter-Cloud and Edge processing conversions which utilize the adjustment power of communication time delay [28], resource availability [29], and processing robustness [30] under a value/cost-driven ambition [31,32] through the deployment of Edge [4] nodes.

Firstly, based on the empirical survey, through synthesizing our collected data, we revealed the influence principles of individual SC of users in the virtual brand community on the internalization of UGC motivation, providing certain guidance for brand managers to focus on target groups, meet their psychological needs, and enhance their intention of UGC.

We further explored the influence of personal traits on UGC motivation internalization from the perspective of community users. Through introducing the theory of self-construal (SC) and self-determination (SD) theory, we revealed the mechanism of the users' characteristics.

Edge nodes can function to aid the network content aggregation with faster speed, more ensured availability, and robust scalability with much cheaper cost among users inside a virtual community and among communities. Since less time delay means more opportunities of participated discussions and deepened opinion exchange, from the implementation perspective, we can add Edge node to increase the local processing power inside communities or switch inefficient Cloud-based processing to efficient nearby Edge nodes to shorten the social distance for users including both independent selfconstrual (IDP-SC) and interdependent self-construal (ITD-SC). Similarly, relative advantages bundled with introducing Edge nodes such as ensured resource availability and enhanced processing robustness can also be employed to enable the conversion between independent self-construal (IDP-SC) and interdependent selfconstrual (ITD-SC).

\section{Empirical theories and models in social network}

2.1 Self-construal theory and self-determination theory

The self-construal theory is widely used to explain how individuals view, define, and explain their relationship with others. Markus and Kitayama explicitly proposed two concepts: ITD-SC and IDP-SC for the first time [22]. ITD-SC values social relationships and tries to fit in with the group. Their behavior is largely determined by how they perceive the thoughts and feelings of those around them. While the IDP-SC pays more attention to maintaining its own autonomy and independence, it does not exclude the establishment and maintenance of harmonious social relations with others, especially when it gains pleasure and benefits $[33,34]$. The self-construal theory has been applied in different areas. In the virtual brand community, members with independent self- 
construal mainly behave themselves, but also interact with others. Customers show both independence and interdependence dimensions without contradiction. Both types of SC have a certain degree of need for social relationships in the virtual brand community. We did the following simplified formulation of ITD-SC and IDP-SC.

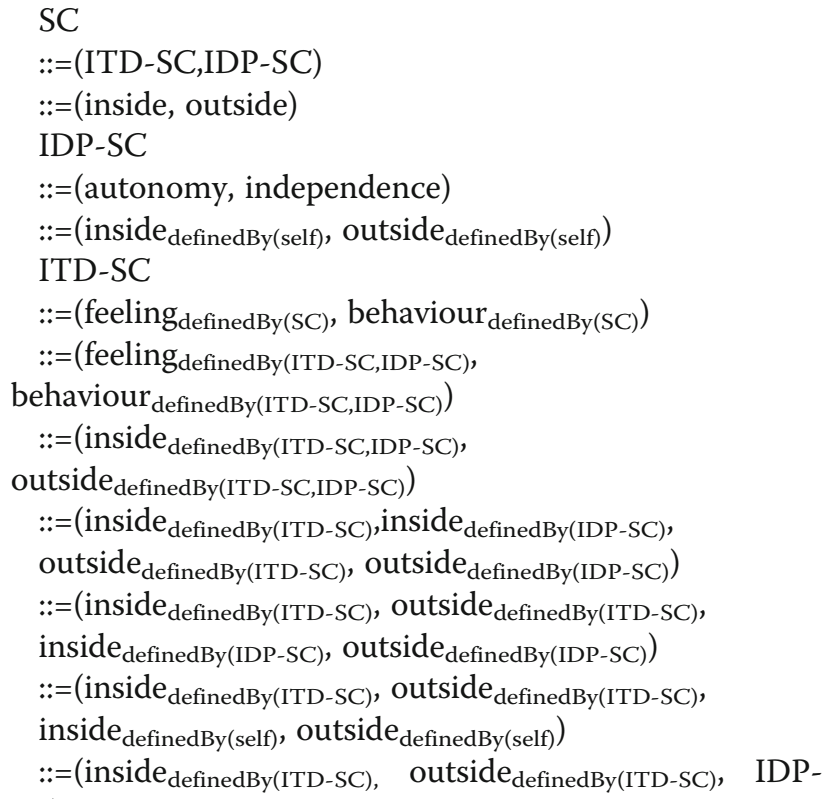

From the above formalization based on the link between human inside and outside divisions, we demonstrate the inclusion relationship between IDP-SC and ITD-SC or the possibility of conversion from IDP-SC to ITD-SC. Actually, every individual has two types of self $[35,36]$ which are tied closely by the networking technology in the virtual brand community which in turn can utilize the difference of the different types of users in term of individuals' cognition, motivation, and emotion and then stimulate certain social behaviors [37-41].

According to the view of self-determination theory, human beings are born with three basic psychological needs, namely, relatedness needs, autonomy needs, and competence needs [42]. Personal motivation is related to these three internal psychological needs, which play an important nutritional role in the internalization of selfmotivation [43]. This internalization process creates a closer psychological attachment to the community and motivates new users to help achieve the community's goals. Meeting basic psychological needs plays an important role in the promotion of the internalization of individual motivation which in turn brings better enjoyment and higher participation of individual, and promotes individuals to stick to a certain activity for a long time and produce more positive behavioral results [1820]. Researches found that the satisfaction of users' perceived RNs can effectively promote the fit between users and the brand community $[46,47]$. Therefore, SD theory can be used to effectively influence $[44,45]$ the internalization mechanism of UGC motivation in the virtual brand community.

Needs(relatedness, autonomy, competence) $)_{\text {self-determina- }}$ tion $\rightarrow$ internalization self-motivation $_{\text {(enjoyment, participation, }}$ stick, behavior)

\subsection{Empirical adaptation of self-construal}

$\mathrm{SC}$ is a stable personality trait, but some scholars believe that SC can be regarded as a state. That is, for the same consumer, his/her SC may change to some extent in different situations and at different points in time. SC can actively regulate the relationship between community interaction and user participation. A person's different self-construal can activate multiple motivations for actual behavior. For example, in the virtual brand community, if users pay more attention to the relationship between themselves and others for interaction, more UGC will be generated such as dissemination and comment. When they see themselves as different from other users, they will produce more unique content. Therefore, we can change the interaction state and behavior mode of users in the virtual brand community by certain means (Fig. 1).

Empirically, we can change the SC state of consumers through certain means and promote the users with independent self-construal (IDP-SC users) to gradually transform to ITD-SC by increasing their communication and interaction with others. In other cases, we set the scene so that he/she thinks he/she is different from others, thus showing his/her independent side. One common tactic is to give consumers a text containing many "I" and ask them to circle all of them. In fact, in the process of circling "I," consumers will inadvertently call their characteristics to mind, thus initiating IDP-SC. If, on the other hand, ITD-SC is needed to be initiated, the consumer can be presented with a similar text in which all the "I" is replaced by "we." By controlling the number and location of Edge nodes, the cost and time of usergenerated content can be changed, and the transformation between IDP-SC and ITD-SC can be realized as required.

\section{Empirical survey design and data analysis}

By testing the hypothesis, we demonstrate that different types of SC users have different degrees of internal motivation to drive users to generate content in the virtual community. Therefore, the feasibility of our proposed mechanism of UGC motivation internalized in the virtual brand community, and guiding the enhancement of the intention of UGC was verified, as the basic of the simulation. 


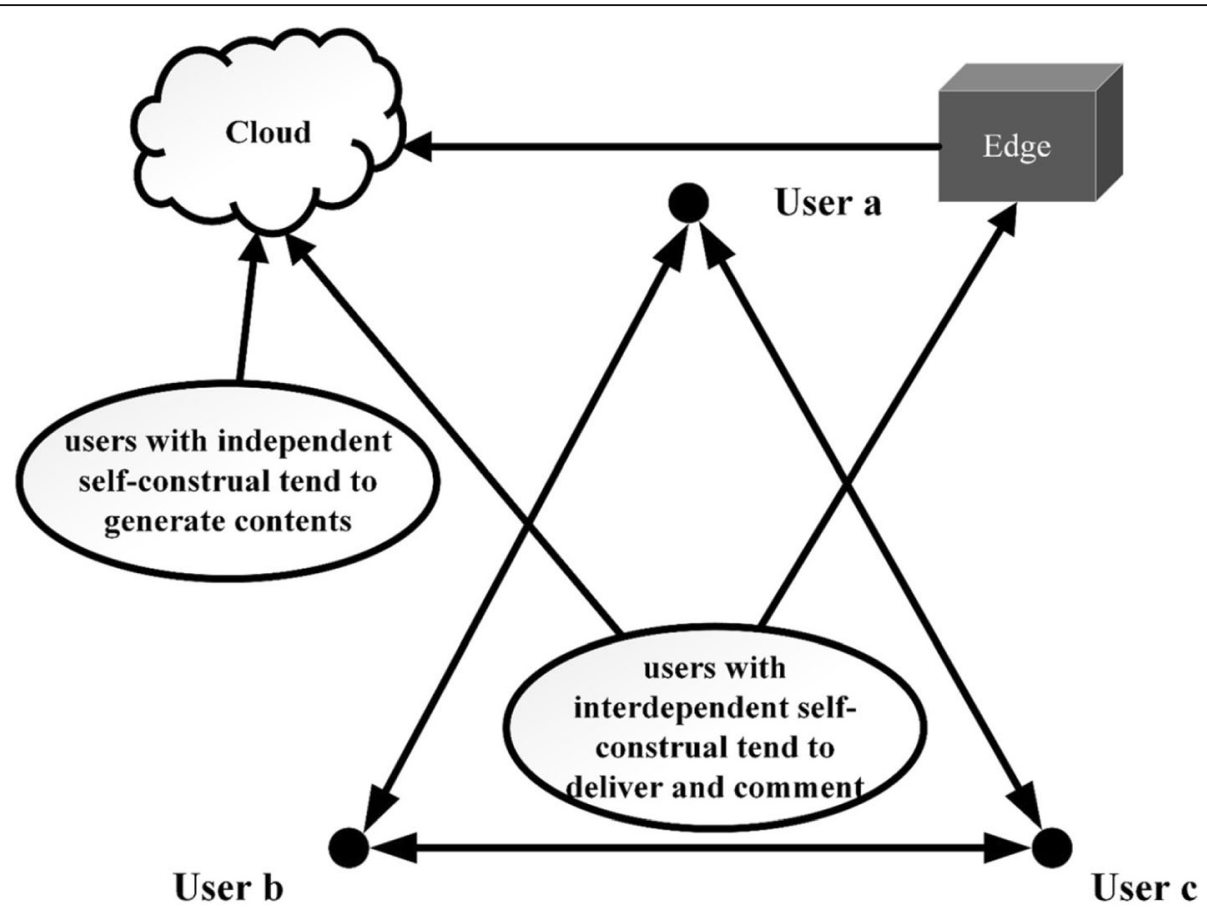

Fig. 1 Attributes and behavioral characteristics of SC in VBC

\subsection{Hypotheses for users}

We have made the following grouped hypotheses for performing the empirical survey in the context of a virtual brand community.

1. The influence of user self-construal (SC) on RNs:

(a) H1: ITD-SC users can positively influence the generation of RNs.

(b) H2: IDP-SC users can also positively influence the generation of RNs.

2. The influence of user self-construal (SC) on selfdetermination (SE) motivation:

(c) H3: IDP-SC users will positively influence the generation of SE motivation.

(d) H4: ITD-SC users will also positively influence the generation of SE motivation.

3. The influence of RNs on the self-determination (SE) motivation:

(e) H5: RNs of users positively influence the SE motivation.

4. The influence of RNs on the intention of UGC:

(f) H6: In the virtual brand community, RNs of users positively influence UGC intention.

5. The influence of self-determination (SE) motivation on UGC intention:

(g) H7: Users' SE motivation positively influences UGC intention.

(h) H8: RNs of users play an intermediary role between ITD-SC and SE motivation. (i) H9: RNs of users play an intermediary role between IDP-SC and SE motivation.

(j) H10: The SE motivation of users plays an intermediary role between the RNs and UGC intention.

\subsection{Index system design and questionnaire design}

The hypothesis model of this paper is summarized according to existing theories and previous empirical studies. The measurement indexes involved in the model are all from the existing literature and modified according to the characteristics of the virtual brand community. The IDP-SC mainly includes four questions, the ITD-SC mainly includes five questions, and the RN, UGC motivation, and UGC intention include four questions. These issues are mainly used to collect the influencing factors when converting between IDP-SC and ITD-SC to support our subsequent simulation (see Table 1 for the specific sources).

In addition to the test items for each variable, this study also added demographic indicators such as basic information, gender, age, education background, occupation, and monthly income of respondents who participated in the virtual brand community. This information is primarily used to factor in the modification of parameter weights in our subsequent simulations. All variables were measured using a 5-point Likert scale, and demographic indicators were designed as options. 
Table 1 Latent variables and indicator sources

\begin{tabular}{|c|c|c|}
\hline $\begin{array}{c}\text { Latent } \\
\text { variables }\end{array}$ & Measurement items & Source \\
\hline IDP-SC & Including four items such as "I like to be different in many ways." & $\begin{array}{c}\text { Singelis (1994); } \\
\text { Wang et al. (2015) }\end{array}$ \\
\hline ITD-SC & Including five items such as "I think the happiness of those around me is my happiness." & $\begin{array}{c}\text { Singelis (1994); } \\
\text { Wang et al. (2015) }\end{array}$ \\
\hline $\mathrm{RN}$ & Including four items such as "I really enjoy being part of the community." & $\begin{array}{c}\text { Nambisan and Baron } \\
(2009)\end{array}$ \\
\hline SE & Including four items such as "It feels great to generate content in the community." & $\begin{array}{l}\text { Thorsten et al. (2004); } \\
\text { Yoo and Gretzel (2008); } \\
\text { Cheng and Lee (2012) }\end{array}$ \\
\hline $\begin{array}{c}\text { UGC } \\
\text { intention }\end{array}$ & Including four items such as "I want to generate content in the community." & $\begin{array}{l}\text { Bock et al. (2005); } \\
\text { Moon and } \operatorname{Kim}(2001)\end{array}$ \\
\hline
\end{tabular}

\subsection{Random sampling survey and data collection}

Since the theoretical model to be tested is built in the context of the virtual brand community, the research object of this paper is all user groups in the virtual brand community. With the development of network technology, various forms of virtual brand communities have rapidly grown, including the official BBS, official Weibo, and fan communication groups, which also provide a great convenience for the investigation of this research.

In the early stage, Singelis' self-construal scale was used for this experiment, with 1-12 items measuring ITD-SC and 13-24 items measuring IDP-SC. We set up a measurement experiment and divided the respondents into 2 groups according to the SC type: IDP-SC and ITD-SC.

The survey began on March 18, 2019, and ended on April 10, 2019, lasting for 22 days and was conducted simultaneously by online and offline questionnaires. A total of 394 questionnaires were issued. Meanwhile, according to the needs of the research purpose, this study also conducted a strict condition screening of the respondents and confirmed the experience of participating in a virtual brand community before filling in the questionnaires. After obtaining the questionnaire, further investigation was conducted to eliminate invalid questionnaires, including checking whether the filling time is less than $1 \mathrm{~min}$ and whether the same scoring options are selected for all questions. Finally, 352 valid questionnaires were collected from 394 questionnaires filled in, with a recovery rate of $89.3 \%$.

\subsection{Descriptive statistical analysis}

Analyzing descriptive statistical results of user basic information in 352 valid questionnaires, most users have been registered as members of the virtual brand community for more than 6 months, and half of all users in the community maintain a higher activity, logins more than 4 times a week. It shows that the respondents have a certain understanding of the virtual brand community and rich participation experience, easy to collect good data for use in our simulations.

A reasonable proportion of men and women participated in the questionnaire survey, 18 to 39 years old young user group accounted for $95 \%$, education background of bachelor degree or above accounted for $86.3 \%, 3000$ yuan or above monthly income of users accounted for $50.9 \%$, and occupation covers students, enterprise employees, self-employed, office personnel, and other industries. This data is basically consistent with the data of the 43rd "Statistical Report on the Development of China's Internet" published by CNNIC in 2019; therefore, the random survey sample has certain representativeness.

We use SPSS 23.0 and AMOS 24.0 for data testing and hypothesis testing, respectively. First of all, the reliability and validity test of the scale can be seen in Tables 2 and 3 . Table 2 shows that Cronbach's alpha coefficient of all latent variables reaches the minimum acceptable critical value of $0.6[9,60]$ and the composite reliability values were also above the threshold of $0.6[60,61]$. It indicates that the measurement of various latent variables is relatively reliable. In terms of validity analysis, Table 2 shows that the standardized factor loading of most indicators is greater than 0.6, and the $T$ value is much higher than 1.96 , which is significant when $p<0.001$. Although the AVE values of latent variables ID and UM are slightly lower than 0.5 , their composite reliability is higher than 0.6 , indicating that the convergent validity of all latent variables is acceptable $[9,62,63]$. The results in Table 3 show that the value of the correlation coefficient between every 
Table 2 Standardized loading of indicators, AVE, composite reliability, and Cronbach's alpha

\begin{tabular}{|c|c|c|c|c|c|}
\hline Indicators & Standardized loading & T value & AVE & $\begin{array}{l}\text { Composite } \\
\text { reliability }\end{array}$ & $\begin{array}{c}\text { Cronbach's } \\
\text { Alpha }\end{array}$ \\
\hline ID1 & 0.61 & & \multirow{4}{*}{0.30} & \multirow{4}{*}{0.63} & \multirow{4}{*}{0.614} \\
\hline ID2 & 0.65 & 7.91 & & & \\
\hline ID3 & 0.45 & 6.28 & & & \\
\hline ID4 & 0.47 & 6.47 & & & \\
\hline ITD1 & 0.68 & & \multirow{5}{*}{0.50} & \multirow{5}{*}{0.80} & \multirow{5}{*}{0.798} \\
\hline ITD2 & 0.60 & 9.72 & & & \\
\hline ITD3 & 0.72 & 11.17 & & & \\
\hline ITD4 & 0.69 & 10.74 & & & \\
\hline ITD5 & 0.66 & 10.45 & & & \\
\hline PN1 & 0.76 & & \multirow{4}{*}{0.64} & \multirow{4}{*}{0.88} & \multirow{4}{*}{0.875} \\
\hline PN2 & 0.78 & 14.81 & & & \\
\hline PN3 & 0.83 & 15.98 & & & \\
\hline PN4 & 0.83 & 15.91 & & & \\
\hline UM1 & 0.73 & & \multirow{4}{*}{0.44} & \multirow{4}{*}{0.76} & \multirow{4}{*}{0.782} \\
\hline UM2 & 0.60 & 10.67 & & & \\
\hline UM3 & 0.69 & 12.31 & & & \\
\hline UM4 & 0.62 & 11.04 & & & \\
\hline UI1 & 0.74 & & \multirow{4}{*}{0.59} & \multirow{4}{*}{0.85} & \multirow{4}{*}{0.848} \\
\hline UI2 & 0.81 & 14.70 & & & \\
\hline UI3 & 0.75 & 13.71 & & & \\
\hline UI4 & 0.75 & 13.66 & & & \\
\hline
\end{tabular}

two latent variables is less than 0.8 , and the square root of AVE is also greater than the correlation coefficient between every two latent variables, indicating that each latent variable has a good discriminant validity [62].

As a systematic error, the common method deviation will greatly affect the effectiveness of the research. First of all, the results of the Harman single-factor test in this study showed that after five factors were extracted, they explained the overall variation of $62.676 \%$, while the level of interpretation of the first factor before rotation did not exceed the critical standard of $40 \%$. Secondly, it can be seen in Table 3 that the maximum correlation

Table 3 Square root of AVE of latent variables and correlation coefficients

\begin{tabular}{cccccc}
\hline $\begin{array}{c}\text { Latent } \\
\text { variables }\end{array}$ & ID & ITD & PN & UM & UI \\
\hline ID & $\mathbf{0 . 5 4 9}$ & & & & \\
\hline ITD & 0.316 & $\mathbf{0 . 6 7 2}$ & & & \\
\hline PN & 0.480 & 0.525 & $\mathbf{0 . 8 0 1}$ & & \\
\hline UM & 0.413 & 0.493 & 0.619 & $\mathbf{0 . 6 6 4}$ & \\
\hline UI & 0.434 & 0.511 & 0.676 & 0.657 & $\mathbf{0 . 7 6 5}$ \\
\hline The average & 3.487 & 3.586 & 3.480 & 3.654 & 3.590 \\
\hline $\begin{array}{c}\text { The } \\
\text { standard } \\
\text { deviation }\end{array}$ & 0.662 & 0.705 & 0.777 & 0.693 & 0.740 \\
\hline $\begin{array}{l}\text { Note: the diagonal value is the square root of AVE } \\
\text { T. }\end{array}$
\end{tabular}


coefficient between potential variables is 0.676 , which is also significantly less than the judgment standard of 0.9 . Therefore, by combining the results of the two tests, it can be said that the common method of this study is not seriously deviated.

The path of the research model was tested. AMOS 24.0 used the maximum likelihood estimation method to calculate the fitting indexes and path coefficient estimates of the model. The test results showed that all the fitting indexes were within the acceptable range, and the research model composed of latent variables had a good fitting degree, including RMSEA $=0.063, \mathrm{RMR}=0.040, \mathrm{CFI}=$ $0.921, \mathrm{GFI}=0.889, \mathrm{AGFI}=0.859, \mathrm{TLI}=0.908, \mathrm{IFI}=$ 0.921 , and $\chi^{2} / \mathrm{df}=2.410$ (Table 4). Therefore, this research model interprets the impact of self-construal on the internalization of UGC motivation. Figure 2 showed the path analysis results in the model, which indicated that the first seven major research hypotheses are supported.

In the final test of mediation, the test methods act as intermediary role adopted by Baron and Kenny has a series of problems [64]. In order to further understand the intermediary role of RNs between $\mathrm{SC}$ of users and SE motivation and the intermediary role of SE motivation between RNs and UGC intention, this study adopted Bootstrap intermediary inspection method, which is widely recommended and used [65], through the PROCESS plug-in in SPSS 23.0 (Table 5).

First, when analyzing the mediating effect of the relatedness needs between interdependent self-construal and self-enhancement motivation, the test results showed that the confidence interval of Bootstrap test under 95\% confidence interval is 0.1918 and 0.3309 , respectively, which did not contain $0, \beta=0.2563$, indicating that the mediating effect of relatedness needs is significant. Secondly, when analyzing the mediating effect of relatedness needs between independent selfconstrual and self-enhancement motivation, the test results showed that the confidence interval of Bootstrap test under $95 \%$ confidence interval is 0.2061 and 0.3589 , respectively, which did not contain $0, \beta=0.2282$, indicating that the mediating effect of relatedness needs is significant. Finally, when analyzing the mediating effect of self-enhancement motivation between relatedness needs and UGC intention, the test results showed that the confidence interval of Bootstrap test under $95 \%$ confidence interval is 0.1480 and 0.3187 , respectively, which did not include $0, \beta=0.2282$, indicating that selfenhancement motivation mediates the relationship between two factors. Based on the above test results, hypotheses $\mathrm{H} 8, \mathrm{H} 9$, and $\mathrm{H} 10$ are supported.

\section{Inter-Cloud and Edge conversion-based concretion of internalization}

\subsection{Interaction modes of network users}

User-generated content (UGC) refers to the content in the form of text, pictures, and video that users voluntarily release on various network platforms [48] exposing user's personal opinions, feelings, and thoughts [49]. Enterprises establish various forms of virtual brand communities to create environments for content creation of users [50]. As SD theory suggests, motivated users consistently produce higher-quality content [51, 52]. The convenient mechanism of content creation in the virtual

Table 4 Hypothesis test results of the structural equation model

\begin{tabular}{|c|c|c|c|c|}
\hline Path & $\begin{array}{l}\text { Unstandardized } \\
\text { path coefficient }\end{array}$ & $\begin{array}{c}\text { Standardized } \\
\text { path } \\
\text { coefficient } \\
\end{array}$ & T value & Results \\
\hline $\mathrm{H} 1: \mathrm{ITD}-\mathrm{SC} \rightarrow \mathrm{RN}$ & 0.498 & 0.425 & $6.404 * * *$ & support \\
\hline $\mathrm{H} 2: \mathrm{IDP}-\mathrm{SC} \rightarrow \mathrm{RN}$ & 0.749 & 0.470 & $5.359 * * *$ & support \\
\hline $\mathrm{H} 3: \mathrm{IDP}-\mathrm{SC} \rightarrow \mathrm{SE}$ & 0.277 & 0.211 & $2.464 *$ & support \\
\hline $\mathrm{H} 4: \mathrm{ITD}-\mathrm{SC} \rightarrow \mathrm{SE}$ & 0.275 & 0.284 & $4.032 * * *$ & support \\
\hline $\mathrm{H} 5: \mathrm{RN} \rightarrow \mathrm{SE}$ & 0.367 & 0.445 & $4.936 * * *$ & support \\
\hline $\begin{array}{l}\text { H6: } \mathrm{RN} \rightarrow \mathrm{UGC} \\
\quad \text { intention }\end{array}$ & 0.288 & 0.365 & $4.495 * * *$ & support \\
\hline $\begin{array}{c}\mathrm{H} 7: \mathrm{SE} \rightarrow \mathrm{UGC} \\
\text { intention }\end{array}$ & 0.527 & 0.552 & $6.126 * * *$ & support \\
\hline \multicolumn{5}{|c|}{ Note: $*$ means $\mathrm{p}<0.05, * *$ means $\mathrm{p}<0.01, * * *$ means $\mathrm{p}<0.001$} \\
\hline
\end{tabular}




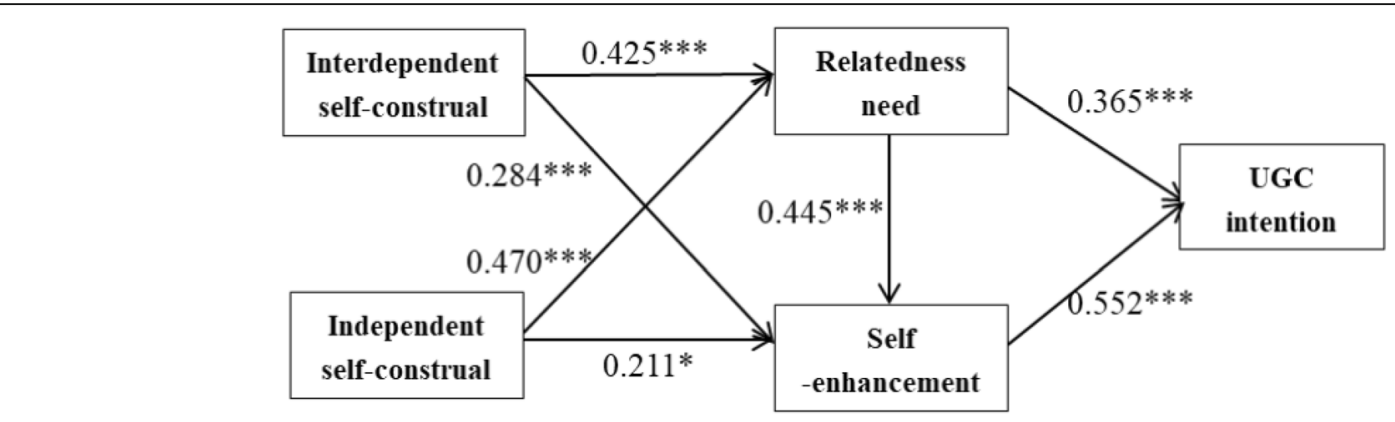

Note: The coefficient value is the standardized path coefficient; $R M S E A=0.063, R M R=0.040$,

$\mathrm{CFI}=0.921, \mathrm{GFI}=0.889, \mathrm{AGFI}=0.859, \mathrm{TLI}=0.908, \mathrm{IFI}=0.921$ and $\chi 2 / \mathrm{df}=2.410$

Fig. 2 Result of model path test

brand community brings great convenience to the users' positive SE [53, 54].

Figure 3 (a) shows an interaction scenario of users of UGC (video, text, pictures, etc.) in a virtual brand community. It consists of three users, including user a, user b, and user $\mathrm{c}$. The interaction modes of these three users in the virtual community can be divided into direct interaction and indirect interaction [55]. In the form of direct interaction, they can directly interact information with everyone. Indirect interaction means that the interaction between the two parties can only be reached by a third party. Therefore, user a will interact with user $\mathrm{c}$ indirectly through user b, i.e., user a-user $\mathrm{c}$ and other forms.

User $_{\text {set }}::=\{$ user a, user b, user c $\}$

Interaction $_{\text {user }}::=\left\{\right.$ Interaction $_{\text {direct }}$, Interaction $\left._{\text {indirect }}\right\}$

Figure 3 (b) shows a network view of the interaction mode of users in the virtual brand community. It consists of two main views, the logical view and the network view. The logical view, shown in Fig. 3 (b), reflects the Interaction $_{\text {direct }}$ and Interaction indirect $_{\text {modes between }}$ users. The network view is a multi-dimensional view of a network space where users interact with each other based on the change of time, location, and transmission of different types of content (video, voice, thumb up, reply, etc.).

Figure 4 shows a graph of user interaction mode based on Cloud computing [56]. The interaction among the users of the virtual brand community is connected to the Cloud through the network and forms a comprehensive platform together with the "cloud" of the Cloud. Users' requests for interaction need to be sent to the Cloud platform first, which is distributed to different machines for simultaneous processing, and then files (video, text, pictures, etc.) are sent to users when they request content. This interactive mode can process a large number of user requests and data at the same time, which is suitable for enterprise promotion, but it has the defects of delay in delivery speed and user experience service. Furthermore, this resource can be wasteful when it does not require a large number of simultaneous data requests.

\subsection{Shifting between Cloud and Edge nodes}

From the engineering perspective, since network resources are always paid or used with cost, to implement the promotion of SD theory for enabling the effective influence on the internalization mechanism of UGC

Table $\mathbf{5}$ Estimated values of Bootstrap mediation analysis coefficients

\begin{tabular}{cccccc}
\hline Mediation path & Effect & S.E. & \multicolumn{2}{c}{ Bootstrap confidence } & Results \\
\cline { 5 - 6 } $\mathrm{H} 8: \mathrm{ITD}-\mathrm{SC} \rightarrow \mathrm{RN} \rightarrow \mathrm{SE}$ & 0.2563 & 0.0353 & 0.1918 & 0.3309 & support \\
\hline $\mathrm{H} 9: \mathrm{IDP}-\mathrm{SC} \rightarrow \mathrm{RN} \rightarrow \mathrm{SE}$ & 0.2747 & 0.0389 & 0.2061 & 0.3589 & support \\
\hline $\mathrm{H} 10: \mathrm{RN} \rightarrow \mathrm{SE} \rightarrow \mathrm{UGC}$ intention & 0.2282 & 0.0430 & 0.1480 & 0.3187 & support \\
\hline
\end{tabular}


(a)

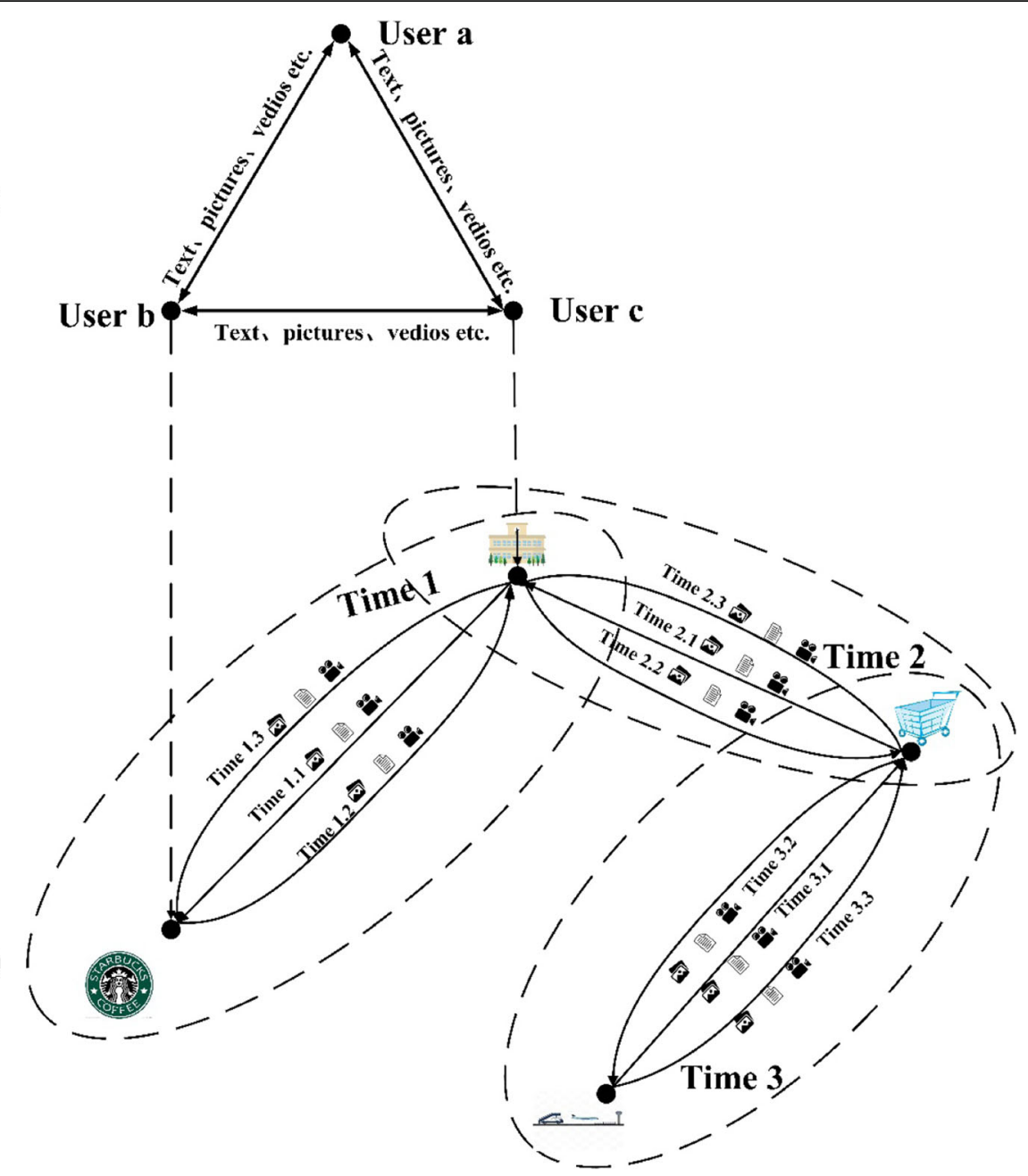

Fig. 3 Interaction scenario of users of UGC in a VBC

motivation in the virtual brand community, we will need to specify the technological concerns to optimize any concrete application of an internalization project. In this work, we give a focus to the adaptation of the workload balance in terms of the inter-conversion between Cloud and Edge computing [57].

Figure 5 shows a graph of user interaction mode based on Edge computing [57]. Through the user interaction mode based on Cloud computing shown in Fig. 4, although multiple users' simultaneous requests can be processed at the same time, different formats of data requests and the connection of a large number of sensors, intelligent terminals, and other network Edge devices produce a large amount of real-time data. Putting requests such as data analysis and processing in the Cloud at the same time will not only bring expensive broadband costs, but also reduce response speed and availability.

Edge computing interaction mode is a service mode that provides Edge intelligence service nearby, prefetch and cache network data near user nodes, satisfies user real-time data request processing, and improves customer experience through ultra-low latency. Depending on individual nodes that do not form the network, peerto-peer transmission of traffic flow through the Cloud is required when running its nodes. Through this mode, we can find that the speed of user interaction is improved and the cost is reduced. Not only that but different forms of interaction can make a significant difference. As shown in the figure, in the process of user interaction, if the service mode based on Cloud computing is adopted, communication in the form of video call for 10 min will consume $1 \mathrm{Mb}$ of bandwidth and cost 2 yuan. Using the Edge computing service mode for communication for $1 \mathrm{~h}$, the cost is reduced to 0.2 yuan/Mb, compared with $1 / 6$ of the cost of Cloud computing. Transferring $300 \mathrm{Mb}$ video to the Cloud between users requires $1-\mathrm{Mb}$ bandwidth and costs 3 yuan. To Edge, the cost is 0.3 yuan.

Therefore, it can be concluded that the shifting from Cloud to Edge computing bidirectionally can potentially 
Fig. 4 Interaction mode of users based on Cloud computing
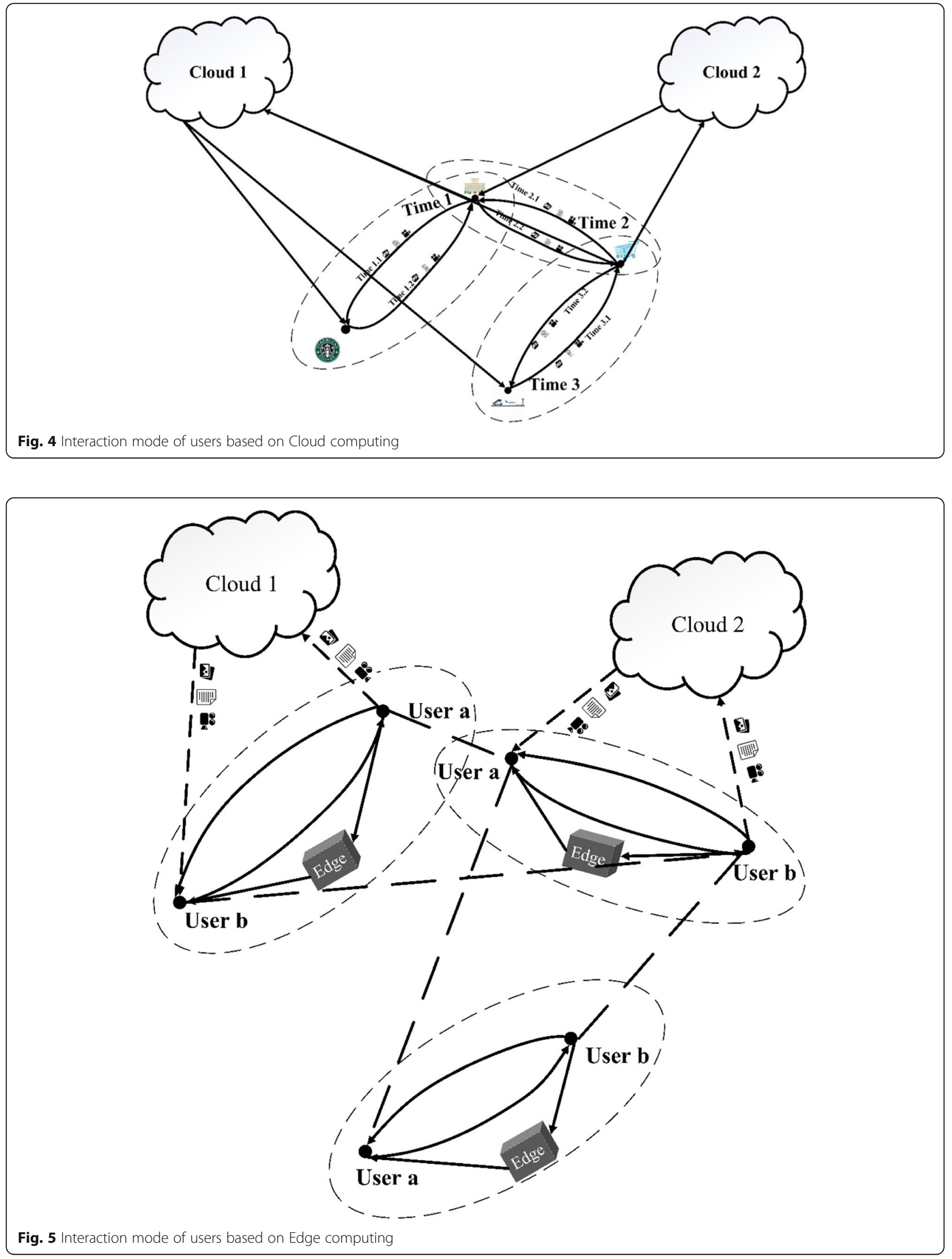
both reduce the cost and shorten the time. So, through employing this conversion mode, potentially the interaction between users will be more frequent, experience is more satisfying, and they are more willing to participate in the interaction. This obvious difference is not only reflected in the interactive forms of video and other texts, but also in the attention of commodities, reply to posts, thumb up, and other interactive behaviors. The UGC behavior model based on Edge computing will make more users have the intention to participate, and the interactive content tends to aggregate. For user precipitation, high-quality users will be more and more.

\section{Simulation}

\subsection{Experiment setup}

To demonstrate the feasibility of our proposed method, we evaluated the design of our proposed solution through numerical simulation. In the simulation Edge architecture, we designed a smart city model, which contains multiple distributed sensors. They collect data and retrieve information bases and reasoning based on a repository, so as to build an attribute database that determines the difference of personnel types. Some of them are the information we obtained through the survey in Section 3. According to the different SC, tested data representing various people are roughly divided into two types, the user with IDP-SC or ITD-SC. We deployed a position sensor to collect data such as location and moving trail of personnel, deployed a video sensor to collect visual data, and then analyzed the collected data to build the attributes database. We determine the types of users by their interaction frequency (including receiving message $(\mathrm{RM})$, collecting information $(\mathrm{Ci})$, sending message (SM), follow-up (Fu), thumb up), as shown in Fig. 6.
We set three parameters, including the change value of each attribute of the user ( $\Delta$ Attributen ${ }^{\text {value }}$ ), the weight of the personal attribute (Attributen ${ }^{\text {weight }}$ ), and user type. In order to facilitate calculation, we set the change value of the personal attribute to the scope between -1 and 1 . We parameterize the type of user; that is, we assume that the value of the most independent self-type user is -1 and that of the most interdependent self-type user is 1 under ideal conditions (please refer to Table 6 for parameter settings).

We evaluated the design process of our proposed solution through numerical simulation, and presented it in the form of algorithm, as shown in Table 7.

We design three experiments to prove that our proposed method is feasible. In experiment 1 , we consider how a change in a single attribute (e.g., the number of Edge nodes) will affect the type of user. In experiment 2, we consider the corresponding relations between related data for all attributes and the types of user. In experiment 3 , we analyzed the error of the experiment during the test. In experiment 4 , we discussed the cost of changing the value of personal attribute.

\subsection{Analysis on results}

In experiment 1 , we validate our proposed method by changing the number of Edge nodes near the people. As shown in Fig. 7, we can select any point as the initial type value for the user, such as the point on the far left. We can change the current type value of the user by increasing or decreasing the number of Edge nodes or increasing the weight of attribute value. It demonstrates that the method we proposed is feasible. Figure 7 also shows the type of user is relative, that is, relatively IDPSC users or relatively ITD-SC users.

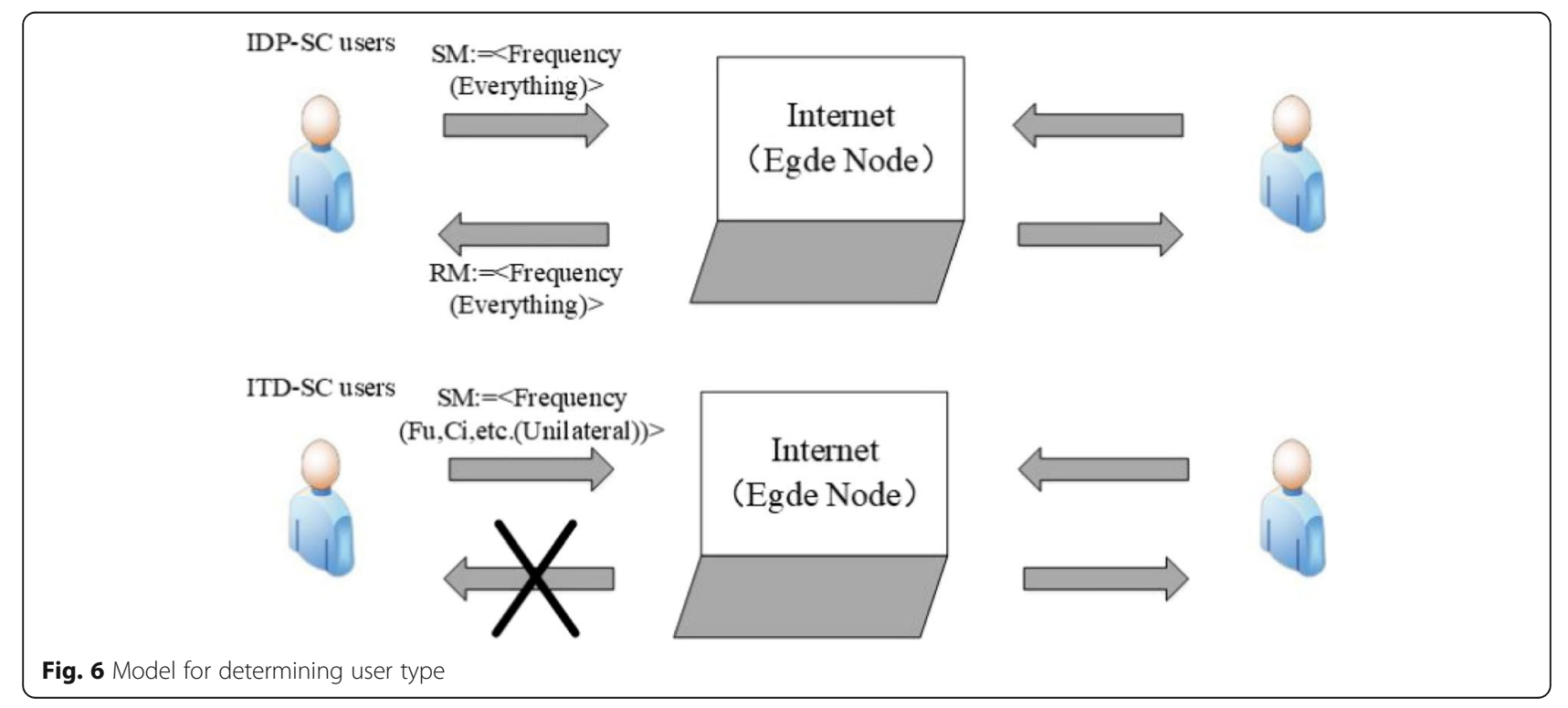


Table 6 Parameter settings of users

\begin{tabular}{|c|c|c|}
\hline Parameters & Value range & Additional information \\
\hline$\triangle$ Attributen $_{\text {value }}$ & {$[-1,1]$} & Normalization processing \\
\hline Attributen $_{\text {weight }}$ & {$[0,1]$} & - \\
\hline User type & {$[-1,1]$} & $\begin{array}{c}\text { Independent } \rightarrow-1 \\
\text { Interdependent } \rightarrow 1\end{array}$ \\
\hline
\end{tabular}

Still taking the point on the far left as an example, when we keep the weight of the attribute value of its Edge node unchanged and increase its attribute value, we can map Table 6 to the two-dimensional plane and know the process that its personnel type value will slowly increase from near -1 to near 1 and then continue to decrease to near -1 . For example, when there is only one family in a village, the lack of communication is manifested as relatively independent users. Then, by increasing the number of Edge nodes, since the convenience of personnel communication is greatly enhanced, the personnel type of users will gradually be changed from IDP-SC to ITD-SC. For another case, if we take the village as a city, its personnel type may be changed between ITD-SC and IDP-SC through increasing or decreasing the Edge nodes. We verify this with the hypotheses that neighbors do not know each other in big cities. In

Table 7 Algorithm description of numerical simulation

\begin{tabular}{|c|}
\hline Algorithm: design process \\
\hline 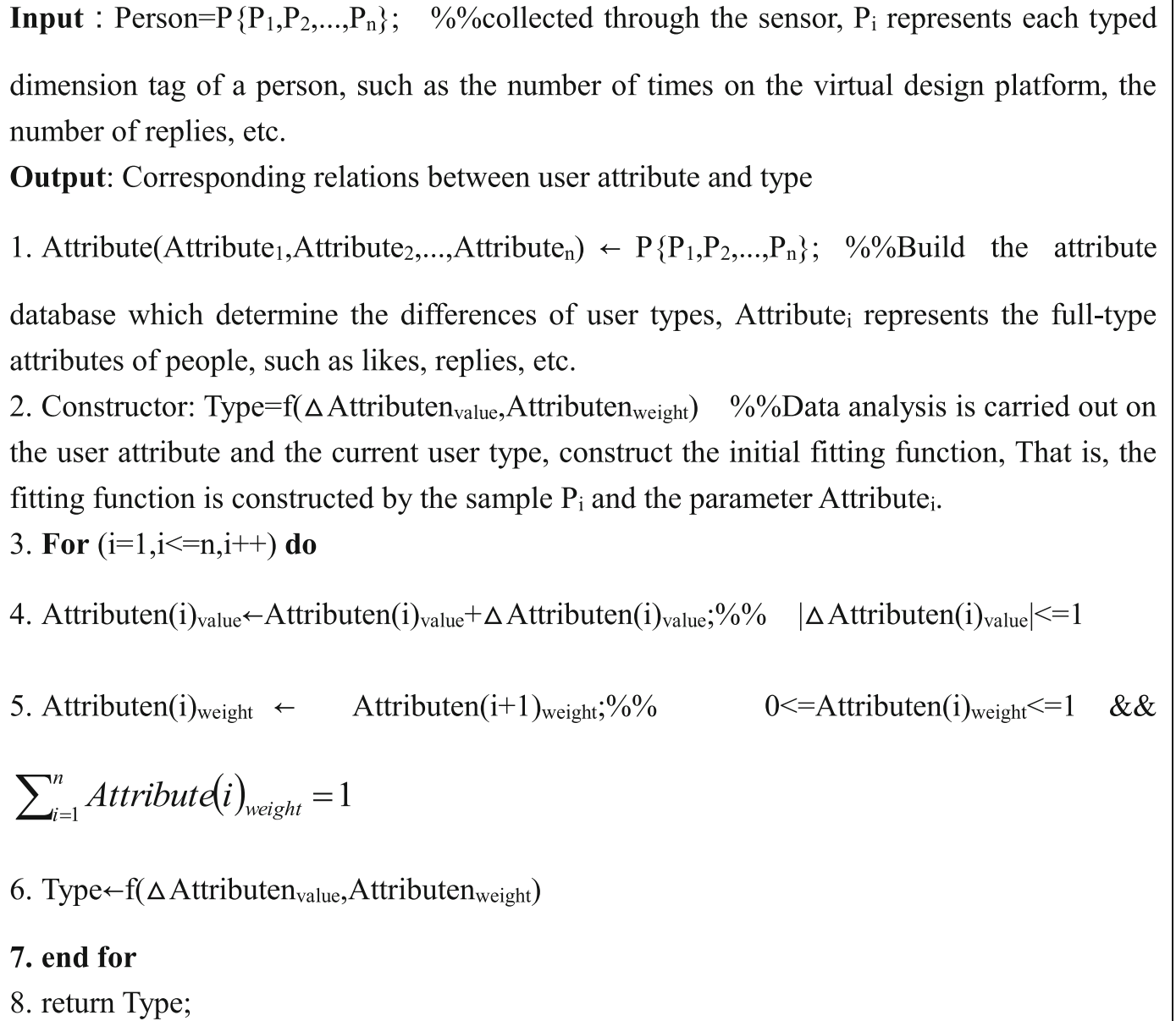 \\
\hline
\end{tabular}




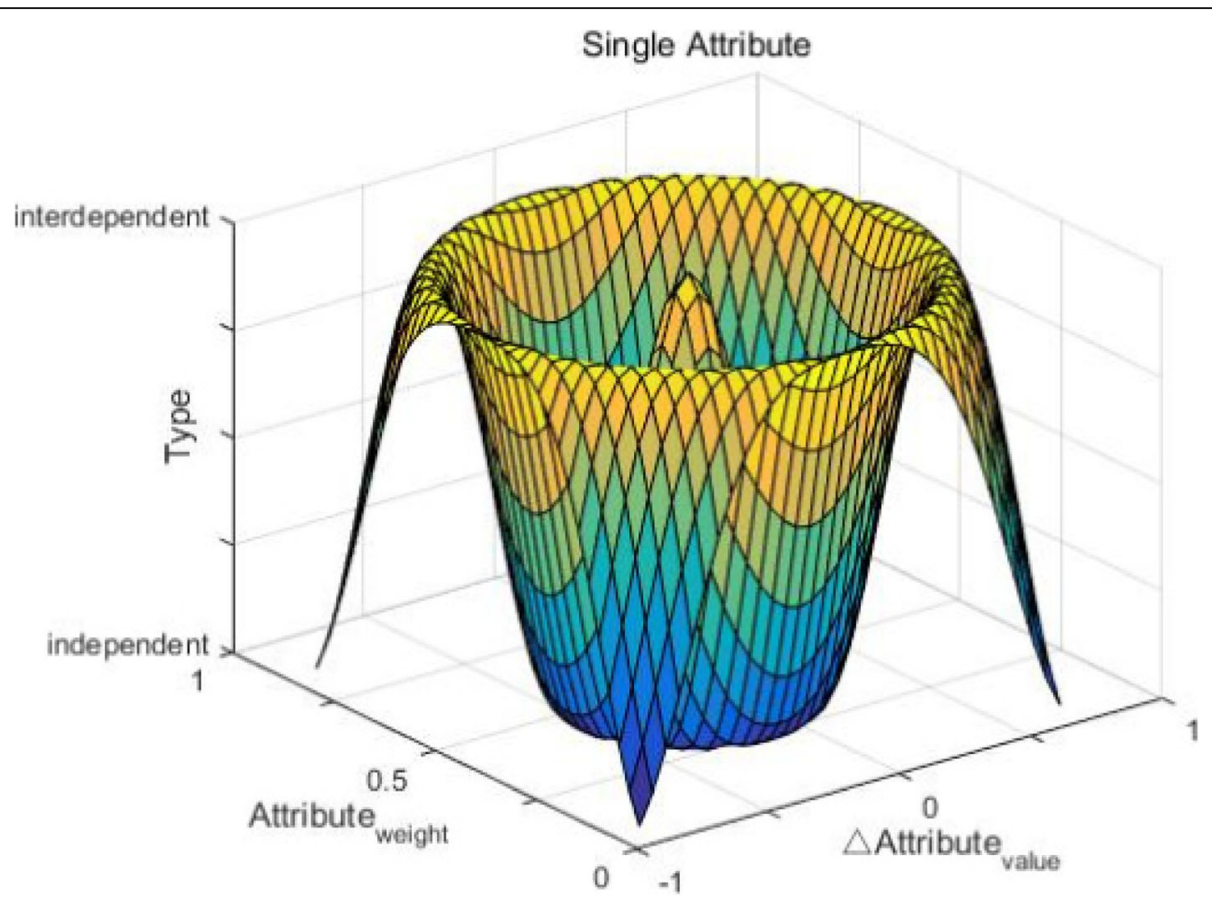

Fig. 7 Single attribute affects the type of users

experiment 1 , we only considered the change of a single attribute one by one; we did not consider such composed change of more than one factor at the current stage.

In experiment 2 , we consider how multiple changes of attributes would affect the type of user. As shown in Fig. 8, we can see that the distribution of personnel types is not stable and irregular. However, we can determine the data information of each attribute, including the change value and weight, through a point in Fig. 8. Still citing the example in experiment 1 , when the number of population

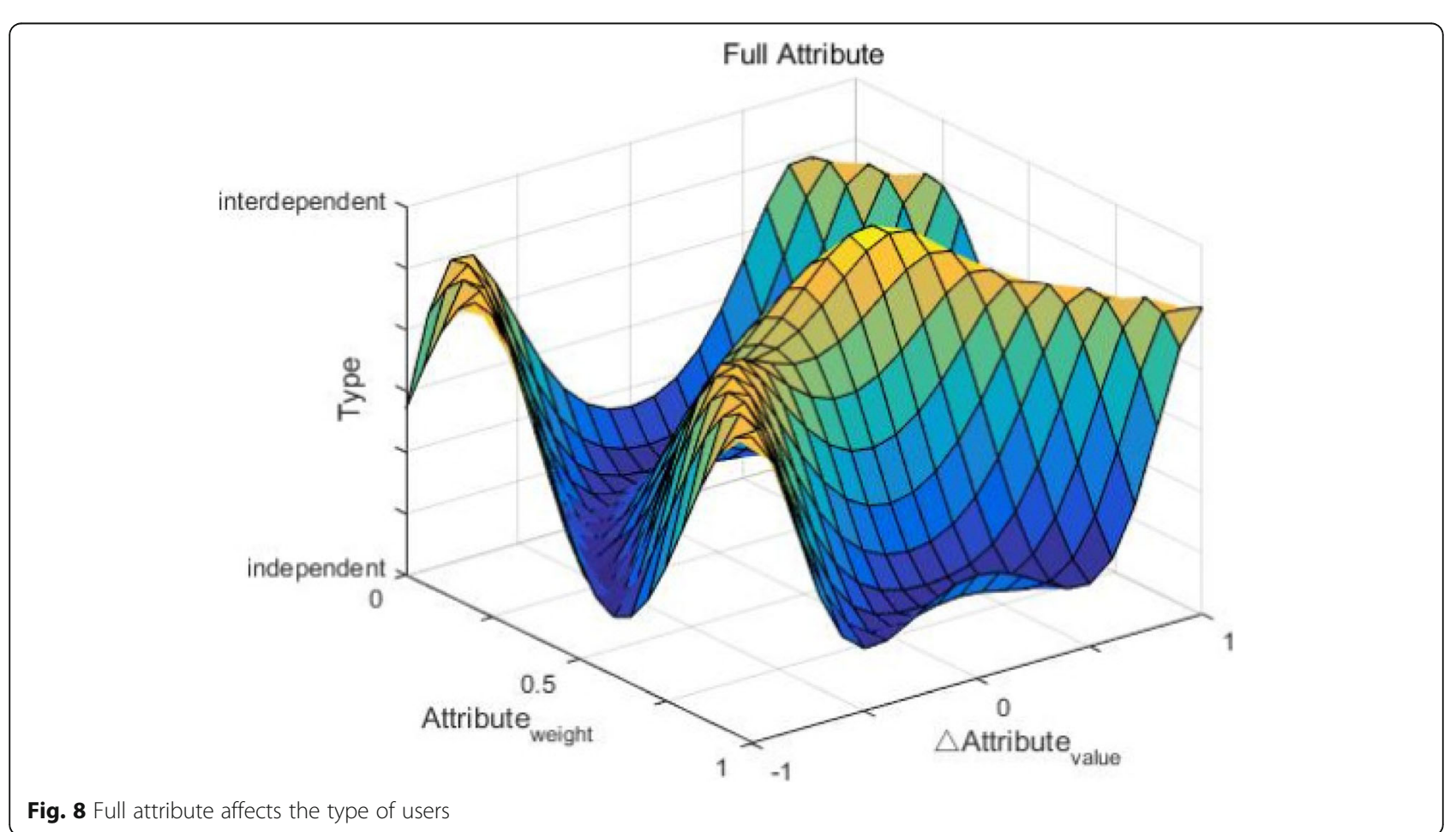


node is increased, all other corresponding attributes will be changed, including communication mode and tool. There are many independent self-users in our simulated cities. Therefore, our proposed method is effective in terms of changing user types through manipulation of the distribution and amount of Edge nodes and Cloud processing.

In experiment 3, we verified the data obtained in Section 3, as shown in Fig. 9. We did ten sets of data tests, in which the solid dots represent the real data obtained from the survey in Section 3, and the hollow dots represent the simulation data we obtained through simulation calculation in experiment 2. The results show that our error rate is acceptable, so the method we proposed is feasible.

In experiment 4, we consider the cost of changing the value and weight of an attribute. As shown in Fig. 10, we define the indicators such as cost, and the calculation of its value covering the transition between Edge computing and Cloud computing. Based on Fig. 10, we observe that there are different costs between transferring a user type to IDP-SC or IDP-SC. It is harder to transfer a user from IDP-SC to IDP-SC than from IDP-SC to IDP-SC. In experiment 4, we show determination on whether to perform a type conversion of users based on its cost. For example, when promoting products in the virtual brand community, interdependent self-users are the main consumer group of this product. The enterprise can consider the cost to decide in which way, namely, the attribute of personnel should lead the user to transform from the independent self-type to the interdependent self-type.

\section{Results and discussion}

The huge amount of knowledge, content, and open and equal communication environment brought by the Internet significantly reduce the psychological burden of users, thus showing more obvious SC characteristics than in the offline real environment, and even generating different needs and motivations. Network IDP-SC users pursue RNs. ITD-SC users pursue SE. Our work creatively introduces the $\mathrm{SC}$ theory into the internalization of the motivation of virtual brand community participation, which provides a fresh perspective for the motivation research of the brand community in a social network. Previous studies have mostly considered the relationship between internal motivation and the IDP-SC, while the research on the ITD-SC considers its relationship with external motivation [52]. Although a few studies have cross-considered the relationship between different SC and motivations, results may be different from the theory due to the social nature of the virtual brand community. Based on an empirical investigation, from surveyed data, we identified the personal characteristics of users that affect the internalization of UGC motivation in the virtual brand community in the current Cloud-dominating networking framework. As Brodie et al. suggested, the virtual brand community is a kind of virtual organizations, members need to accept the community and the value of the brand concept, establish social relationships with other members, involve in the community, especially the IDP-SC users [14]. The reason why the community is able to attract them to participate

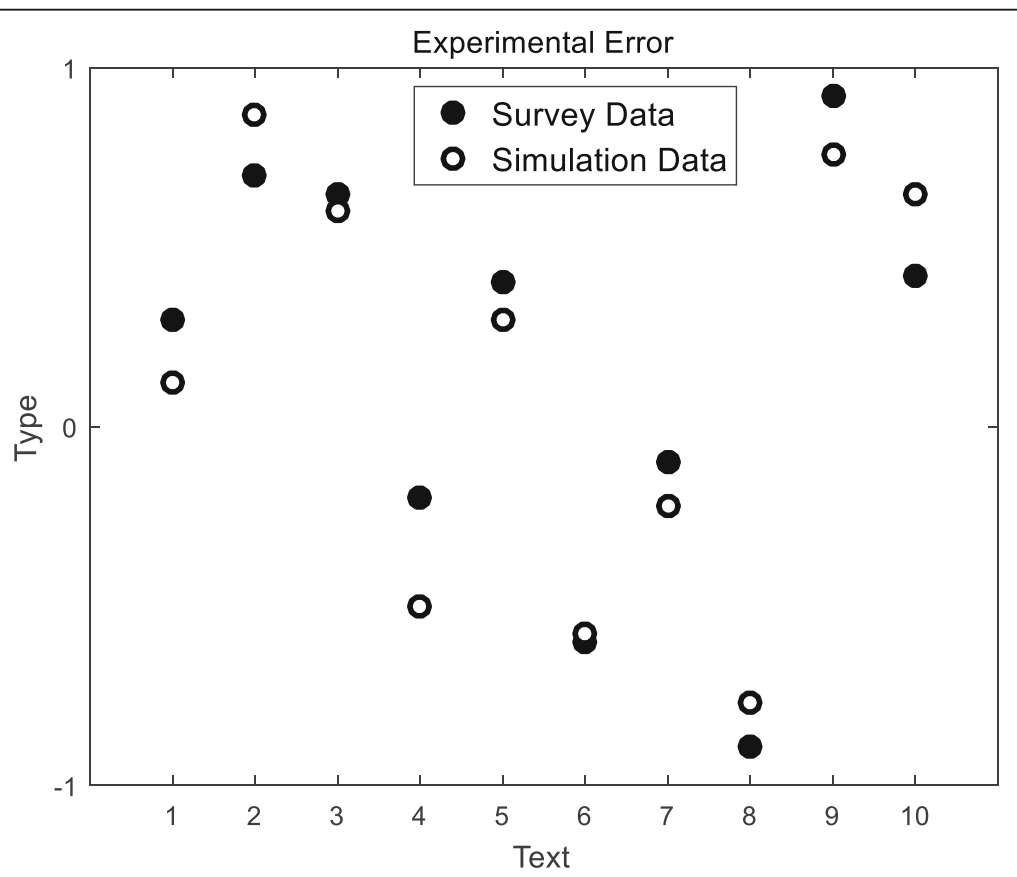

Fig. 9 Error in experimental test 


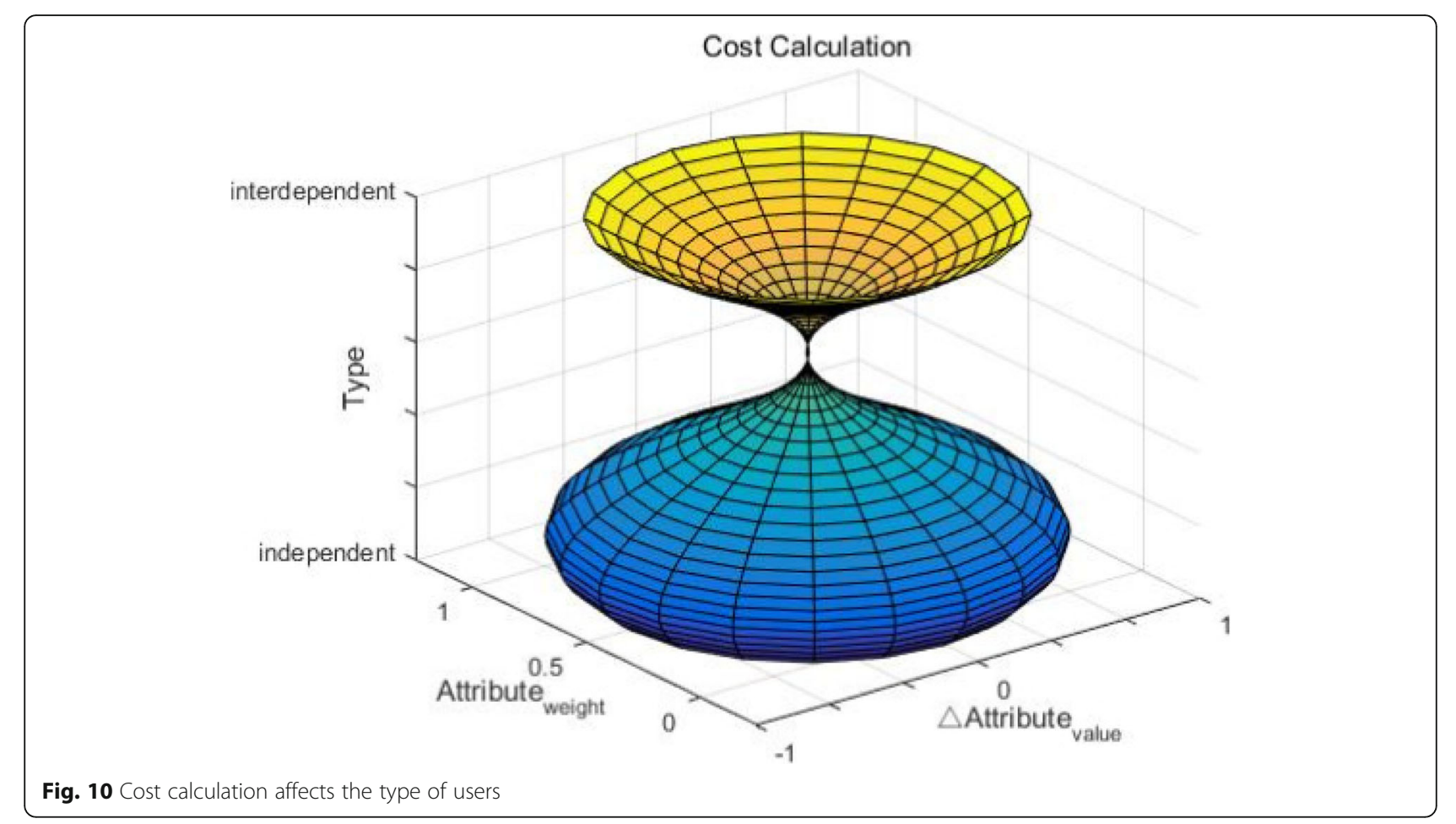

in and conduct UGC behavior is largely because the relational network can well meet its internal motivation.

Based on SC theory and SD theory and our conducted data analysis, we found that, in the virtual brand community in the current Cloud environment, IDP-SC users have RNs while ITD-SC users have stronger RNs. If viewed through the attributes of the virtual brand community, the above phenomenon can be explained as that the core asset of virtual brand community is in proportion to the strength of the interaction and communication between enterprises and users through the networking facilities, and between users and users mediated through created content, thus forming a set of social relations [43, 59]. Therefore, the pursuit of satisfying the RNs of users and strengthen the associations between users has become the main target of enterprises. For network ITD-SC users, they are eager to integrate into the network group and maintain harmony and close communication with networked others. The existence of the virtual brand community in the Cloud exactly provides them with this scene. Network IDP-SC users have a stronger desire to establish a positive identification or identity in the virtual brand community, to show their own professional knowledge and status. They often achieve their identity through UGC behavior mechanism in a networked community, such as following, liking, reply, and collection. That is to say, the RNs of IDP-SC users are more based on those who can promote the behavior of the $\mathrm{SE}$, because it meets their narcissism tendency [58] and the pursuit of their own unique and individuals' positive affirmation and evaluation to themselves. IDP-SC users seek to establish its own centered relationship network in the community. On the other hand, this also confirms the view that IDP-SC users will actively seek to establish social relations after perceiving fun and value [30]. Previous studies often conclude that ITD-SC users have a high tendency of external motivation. However, based on our survey, we found that the patterns embodied in the collected data correspond to that in the virtual brand community, ITD-SC also has a strong internal motivation of SE, and the RNs plays an important intermediary role.

The RNs of community users can enhance UGC intention through SE of this internal motivation, which further confirms the view of SD theory; that is, the satisfaction of basic psychological needs plays an important nutritional role in the internal motivation of users and then affects the behavioral intention of users. Therefore, enhanced network bandwidth, shortened time delay between communications, more ensured availability of networked content and resource, and strengthened network robustness can provide a foundation for adjustment of the strength of the association among users and therefore potentially converting between IDP-SC and ITD-SC in terms of UGC behavior details. From a technical perspective, adaptation and deployment of emerging applications of Edge computing can fulfill the function of adjustment of the network bandwidth, communication time delay, and resource availability and performance, among networked users, with a remarkably lower facility cost or investment. 


\section{Research conclusions and future directions}

By introducing the self-determination (SD) theory and combining the relationship attribute of the virtual brand community in inter-Cloud and Edge conversions and adaptation, this study creatively investigated the relatedness needs (RNs) with different types of self-construal (SC) of users from an information implementation perspective. Based on the empirical survey, our analysis has revealed how the user's personality traits affect the internalization of motivation through relatedness needs (RNs), which makes up for the deficiency of the internalization of motivation in previous studies and further expands the application scope of self-determination (SD) theory. Hereafter, we create a simulation of the interCloud and Edge conversions of the interactions among various SC users with MATLAB to validate the feasibility of our proposed conversion mechanism between interdependent self-construal (ITD-SC) and independent self-construal (IDP-SC) users to reach the goal of manipulating the amount and the quality of UGC to serve the business or social goals. Future research may consider using more sophisticated experimental methods to precisely initiate users' self-construal (SC) types and validate the simulation with a large scale of field data with multiple countries, regions, industries, and brands to improve the representativeness. Future research will also consider more types of internal motivation and study the differences among various motivations of users.

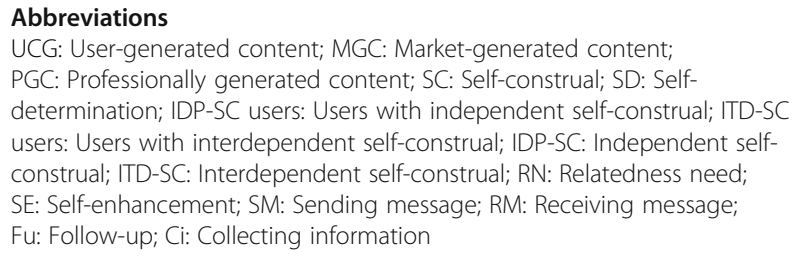

\section{Acknowledgements}

This paper is supported by NSFC under Grant (No. 61662021 and No. 61363007), and CERnet Innovation Project No. NGll20180607.

\section{Authors' contributions \\ MS was responsible for the drafting of the main part of this paper and designed and implemented the experiment. YD provides the initial solution of the integration of inter-Edge and Cloud conversion for the conversion of different types of users. TH provides many concrete details and figures and formatted the whole paper. LZ provides the simulation demonstration. All authors read and approved the final manuscript.}

\section{Funding}

National Natural Science Foundation of China No. 61662021. National Natural Science Foundation of China No. 61363007. CERnet Innovation Project No. NGII20180607.

\section{Availability of data and materials}

Data sharing is not applicable to this article as no datasets were generated or analyzed during the current study.

\section{Competing interests}

The authors declare that they have no competing interests.
Received: 19 September 2019 Accepted: 29 December 2019

Published online: 10 January 2020

\section{References}

1. G. Pallis, Cloud computing: the new frontier of Internet computing. IEEE internet computing 14(5), 70-73 (2010)

2. Qi, L., Chen, Y., Yuan, Y., Fu, S., Zhang, X., \& Xu, X.: A QoS-aware virtual machine scheduling method for energy conservation in cloud-based cyberphysical systems. World Wide Web, 1-23 (2019).

3. M. Satyanarayanan, The emergence of edge computing. Computer 50(1), 30-39 (2017)

4. L. Qi, X. Zhang, W. Dou, C. Hu, C. Yang, J. Chen, A two-stage localitysensitive hashing based approach for privacy-preserving mobile service recommendation in cross-platform edge environment. Future Generation Computer Systems 88, 636-643 (2018)

5. M.E. Zaglia, Brand communities embedded in social networks. Journal of Business Research 66(2), 216-223 (2013)

6. H. Liu, H. Kou, C. Yan, L. Qi, Link prediction in paper citation network to construct paper correlation graph. EURASIP Journal on Wireless Communications and Networking 1, 1-12 (2019)

7. M. Royo-Vela, P. Casamassima, The influence of belonging to virtual brand communities on consumers' affective commitment, satisfaction and wordof-mouth advertising: the ZARA case. Online Information Review 35(4), 517542 (2011)

8. M. Scholz, J. Schnurbus, H. Haupt, V. Dorner, A. Landherr, F. Probst, Dynamic effects of user-and marketer-generated content on consumer purchase behavior: modeling the hierarchical structure of social media websites. Decision Support Systems 113, 43-55 (2018)

9. M. Demiray, S. Burnaz, Exploring the impact of brand community identification on Facebook: firm-directed and self-directed drivers. Journal of Business Research 96, 115-124 (2019)

10. B. Choi, I. Lee, Trust in open versus closed social media: the relative influence of user-and marketer-generated content in social network services on customer trust. Telematics and Informatics 34(5), 550-559 (2017)

11. K.-Y. Goh, C.-S. Heng, Z. Lin, Social media brand community and consumer behavior: quantifying the relative impact of user-and marketer-generated content. Information Systems Research 24(1), 88-107 (2013)

12. C.-C. Wu, Y.-J. Chen, C.-J. Wang, Is persuasive advertising always combative in a distribution channel? Marketing Science 28(6), 1157-1163 (2009)

13. W. Gong, L. Qi, Y. Xu, Privacy-aware multidimensional mobile service quality prediction and recommendation in distributed fog environment (Wireless Communications and Mobile Computing, 2018)

14. Ding, Y., Phang, C.W., Lu, X., Tan, C.-H., Sutanto, J.: The role of marketer-and user-generated content in sustaining the growth of a social media brand community. In: 2014 47th Hawaii International Conference on System Sciences, pp. 1785-1792 (2014)

15. Y. Sun, X. Dong, S. McIntyre, Motivation of user-generated content: social connectedness moderates the effects of monetary rewards. Marketing Science 36(3), 329-337 (2017)

16. T. Van Mierlo, The $1 \%$ rule in four digital health social networks: an observational study. Journal of Medical Internet Research 16(2), 33 (2014)

17. Gurbaskan Akyuz, B.: Factors that influence local food consumption motivation and its effects on travel intentions. Anatolia, 1-10 (2019)

18. J.T. Matikainen et al., Motivations for content generation in social media (Participations, Journal of Audience and Reception Studies, 2015)

19. R.M. Ryan, J.P. Connell, Perceived locus of causality and internalization: examining reasons for acting in two domains. Journal of Personality and Social Psychology 57(5), 749 (1989)

20. J.P. Connell, J.G. Wellborn, Competence, autonomy, and relatedness: a motivational analysis of self-system processes (1991)

21. J.U. Islam, Z. Rahman, L.D. Hollebeek, Consumer engagement in online brand communities: a solicitation of congruity theory. Internet Research 28(1), 23-45 (2018)

22. H.R. Markus, S. Kitayama, Culture and the self: implications for cognition, emotion, and motivation. Psychological Review 98(2), 224 (1991)

23. Y. Wang, S.S. Ma, D. Li, Customer participation in virtual brand communities: the self-construal perspective. Information \& Management 52(5), 577-587 (2015)

24. Garnefeld, I., Helm, S.V.: Engineered customer referrals: prevalence and antecedents. In: Marketing Challenges in a Turbulent Business Environment, pp. 1-6. Springer, ??? (2016) 
25. S. Kamboj, B. Sarmah, S. Gupta, Y. Dwivedi, Examining branding co-creation in brand communities on social media: applying the paradigm of stimulusorganism-response. International Journal of Information Management 39, 169-185 (2018)

26. F.X. Yang, Effects of restaurant satisfaction and knowledge sharing motivation on eWOM intentions: the moderating role of technology acceptance factors. Journal of Hospitality \& Tourism Research 41(1), 93-127 (2017)

27. Toubia, O., Stephen, A.T.: Intrinsic vs. image-related utility in social media: why do people contribute content to twitter? Marketing Science 32(3), 368392 (2013)

28. Zhang, K., Mao, Y., Leng, S., Maharjan, S., Zhang, Y.: Optimal delay constrained offloading for vehicular edge computing networks. In: 2017 IEEE International Conference on Communications (ICC), pp. 1-6 (2017)

29. Mahmud, M., Buyya, R.: "fog computing: a taxonomy, survey and future directions," internet of everything: algorithms, methodologies, technologies and perspectives (2016)

30. Antonopoulos, N., Gillam, L.: Cloud computing. Springer, ??? (2010)

31. Sullivan, P.H.: Value driven intellectual capital: how to convert intangible corporate assets into market value. John Wiley \& Sons, Inc., ??? (2000)

32. Y. Duan, Z. Lu, Z. Zhou, X. Sun, J. Wu, Data privacy protection for edge computing of smart city in a DIKW architecture. Engineering Applications of Artificial Intelligence 81, 323-335 (2019)

33. A.P. Fiske, Relativity within moose ("mossi") culture: four incommensurable models for social relationships. Ethos 18(2), 180-204 (1990)

34. E.E. Sampson, The debate on individualism: Indigenous psychologies of the individual and their role in personal and societal functioning. American Psychologist 43(1), 15 (1988)

35. A. Kiuchi, Independent and interdependent self-construals: ramifications for a multicultural society 1. Japanese Psychological Research 48(1), 1-16 (2006)

36. V. Dogan, Why do people experience the fear of missing out (FoMO)? exposing the link between the self and the FoMO through self-construal. Journal of Cross-Cultural Psychology 50(4), 524-538 (2019)

37. M. Shim, R.J. Lee-Won, S.H. Park, The self on the net: the joint effect of selfconstrual and public self-consciousness on positive self-presentation in online social networking among South Korean college students. Computers in Human Behavior 63, 530-539 (2016)

38. J.F. Moses, P.C. Dwyer, P. Fuglestad, J. Kim, A. Maki, M. Snyder, L. Terveen, Encouraging online engagement: the role of interdependent self-construal and social motives in fostering online participation. Personality and Individual Differences 133, 47-55 (2018)

39. E. Akpinar, P.W. Verlegh, A. Smidts, Sharing product harm information: the effects of self-construal and self-relevance. International Journal of Research in Marketing 35(2), 319-335 (2018)

40. C.Y. Chen, Who I am and how I think: the impact of self-construal on the roles of internal and external reference prices in price evaluations. Journal of Consumer Psychology 19(3), 416-426 (2009)

41. S.E. Cross, E.E. Hardin, B. Gercek-Swing, The what, how, why, and where of self-construal. Personality and Social Psychology Review 15(2), 142-179 (2011)

42. R.M. Ryan, E.L. Deci, Intrinsic and extrinsic motivations: classic definitions and new directions. Contemporary Educational Psychology 25(1), 54-67 (2000)

43. C. Yoon, E. Rolland, Knowledge-sharing in virtual communities: familiarity, anonymity and self-determination theory. Behaviour \& Information Technology 31(11), 1133-1143 (2012)

44. W. Gao, Y. Liu, Z. Liu, J. Li, How does presence influence purchase intention in online shopping markets? An explanation based on self-determination theory. Behaviour \& Information Technology 37(8), 786-799 (2018)

45. M. Thomson, Human brands: investigating antecedents to consumers' strong attachments to celebrities. Journal of Marketing 70(3), 104-119 (2006)

46. Fu, J., Ko, P.-C., Lu, C., Lee, W.-L.: Brand engagement and co-creation in the online environments-based on the self-determination theory. In: Proceedings of the 2018 International Conference on E-business and Mobile Commerce, pp. 11-16 (2018). ACM

47. B.J. Baldus, C. Voorhees, R. Calantone, Online brand community engagement: scale development and validation. Journal of Business Research 68(5), 978-985 (2015)
48. X. Wang, Y. Li, How trust and need satisfaction motivate producing usergenerated content. Journal of Computer Information Systems 57(1), 49-57 (2017)

49. H. Akrout, G. Nagy, Trust and commitment within a virtual brand community: the mediating role of brand relationship quality. Information \& Management 55(8), 939-955 (2018)

50. K. Crowston, I. Fagnot, Stages of motivation for contributing user-generated content: a theory and empirical test. International Journal of HumanComputer Studies 109, 89-101 (2018)

51. Garud, R., Kumaraswamy, A.: Vicious and virtuous circles in the management of knowledge: the case of INFOSYS technologies. MIS quarterly 29(1) (2005)

52. Lou, J., Fang, Y., Lim, K.H., Peng, J.Z.: Contributing high quantity and quality knowledge to online Q\&A communities. Journal of the American Society for Information Science and Technology 64(2), 356-371 (2013)

53. H. Cai, C. Sedikides, L. Gaertner, C. Wang, M. Carvallo, Y. Xu, E.M. O'Mara, L.E. Jackson, Tactical self-enhancement in China: is modesty at the service of self-enhancement in East Asian culture? Social Psychological and Personality Science 2(1), 59-64 (2011)

54. C.W. Yoo, G.L. Sanders, J. Moon, Exploring the effect of e-WOM participation on e-Loyalty in e-commerce. Decision Support Systems 55(3), 669-678 (2013)

55. J. Hong, H.H. Chang, "I" follow my heart and "we" rely on reasons: the impact of self-construal on reliance on feelings versus reasons in decision making. Journal of Consumer Research 41(6), 1392-1411 (2015)

56. J.Y. Ho, M. Dempsey, Viral marketing: motivations to forward online content. Journal of Business Research 63(9-10), 1000-1006 (2010)

57. M. De Angelis, A. Bonezzi, A.M. Peluso, D.D. Rucker, M. Costabile, On braggarts and gossips: a self-enhancement account of word-of-mouth generation and transmission. Journal of Marketing Research 49(4), 551-563 (2012)

58. A.H. Jordan, P.G. Audia, Self-enhancement and learning from performance feedback. Academy of Management Review 37(2), 211-231 (2012)

59. Q. Zhao, C.-D. Chen, H.-W. Cheng, J.-L. Wang, Determinants of live streamers' continuance broadcasting intentions on twitch: a selfdetermination theory perspective. Telematics and Informatics 35(2), $406-$ 420 (2018)

60. R.M. Baron, D.A. Kenny, The moderator-mediator variable distinction in social psychological research: conceptual, strategic, and statistical considerations. Journal of Personality and Social Psychology 51(6), 1173 (1986)

61. K.J. Preacher, A.F. Hayes, SPSS and SAS procedures for estimating indirect effects in simple mediation models. Behavior Research Methods, Instruments, \& Computers 36(4), 717-731 (2004)

62. S. Aryee, F.O. Walumbwa, E.Y. Seidu, L.E. Otaye, Impact of high-performance work systems on individual-and branch-level performance: test of a multilevel model of intermediate linkages. Journal of Applied Psychology 97(2), 287 (2012)

63. M. Sicilia, M. Palaz'on, Brand communities on the internet: a case study of Coca-Cola's Spanish virtual community. Corporate Communications: An International Journal 13(3), 255-270 (2008)

64. E. Rohmann, S. Hanke, H.-W. Bierhoff, Grandiose and vulnerable narcissism in relation to life satisfaction, self-esteem, and self-construal. Journal of Individual Differences (2019)

65. A.H. Maslow, A theory of human motivation. Psyhological Review. Psychological Review 1, 943 (1943)

\section{Publisher's Note}

Springer Nature remains neutral with regard to jurisdictional claims in published maps and institutional affiliations. 